
\title{
25 Research Square \\ The Impact of Knowledge on the Formation of Attitudes Towards Ageing and the Elderly
}

Iris Jerončić Tomić

University of Split

Mia Britvić

University of Split

Rosanda Mulić ( $\square$ rosanda@pfst.hr)

University of Split

Nikola Kolja Poljak

University of Split

\section{Research Article}

Keywords: attitudes, ageing, education

Posted Date: April 19th, 2021

DOl: https://doi.org/10.21203/rs.3.rs-414315/v1

License: (c) (i) This work is licensed under a Creative Commons Attribution 4.0 International License. Read Full License 


\section{Abstract}

Background: With the global trend towards an increasing aging population, there is a corresponding increase in the health problems associated with elderly population. Older people need more and more health services. According to the fews research, influencing factors on health care practice of the health workers towards the elderly in geriatric hospitals included knowledge, attitude, and gerontological education.

Objective: The aim of this study was to determine if education in gerontology affects attitude towards ageing and the elderly among students at the University of Split. An additional objective was to determine the extent to which the students' socio-demographic status (age, sex, domicile), different education and experience of life with the elderly affect their attitude towards ageing and the elderly.

Methods: The population included in this study consisted of 301 students of the University of Split, 153 of whom attended the Faculty of Maritime Studies and 148 the School of Medicine. A total of 45 students had attended training in gerontology, while 265 had none. Information was gathered through a questionnaire that consisted of 3 parts: one investigating their socio-demographic characteristics, another looking into their attitudes towards the elderly (the Kogan score scale) and Palmer's competence test.

Results: A difference in attitude has been observed between students who had had training in gerontology compared to those who had none. Socio-demographic factors, different education and the experience of life with the elderly also affect student attitudes. Overall, School of Medicine students had a more positive attitude than those of the Faculty of Maritime Studies.

Conclusion: Education in gerontology helps form a more positive attitude towards the elderly among students, meaning that educational programs should be changed with the aim of reducing the stigmatization of the elderly.

\section{Introduction}

People nowadays live longer and exhibit a growing need for an improved quality of life. Contagious disease prevalence has decreased as medical science evolved. As a result of successful vaccination, of the administration of antibiotics and other forms of treatment, the morbidity and mortality caused by contagious diseases have decreased. On the one hand, progress in medicine, coupled with the discovery of a number of medications, the application of various forms of treatment and new diagnostic and therapeutic opportunities, provides for better knowledge and earlier disease detection, as well as better and more effective treatment of chronic illnesses. On the other hand, the issue of care for an ever increasing number of chronic patients is rising in importance. An ageing population is a global phenomenon; however, this issue is predominantly discussed in developed countries (1). In fact, most developed countries have low fertility and birth rates as a result of demographic transition. Extended life expectancy has contributed to a rise in the share of elderly persons in the total population. Medical 
advances, especially in prevention and treatment, have also played a major role in increasing life expectancy, along with improved socioeconomic conditions, which has resulted in decreased mortality rates (2). Accelerated and continuous growth of elderly population is a demographic trend that increases the need for medical and social services, since the elderly are the most frequent users of such services (3). An ageing population thus turns into a key issue of social development, with a substantial expected impact on the situation in health care, social care and social policy throughout the 21st century. Population ageing is a highly complex process that entails major economic, social and political consequences (4). At the global level, the number of elderly persons is continuously rising as a result of progress in medicine that has lead to an extension of life expectancy to between 80 and 90 years (1).

A longer life brings along opportunities, not only for the elderly and their families, but also for society as a whole (5). Additional years of life provide an opportunity to start new activities, such as further education, a new career, or pursuit of a neglected passion from the past. Elderly persons contribute to their families and communities in many ways. The scope of these opportunities and contributions largely depends on a single factor: health (4).

\section{Demographic Profile of Croatia and the World}

The United Nations data available in the "World Population Prospects 2019" point to an eight-year increase in average life expectancy between 1990 and 2019. In 2019, global average life expectancy stood at 72.6 years. An even higher increase is expected until 2050, with average life expectancy estimated at 77.1 years $(6)$.

According to data of the Bureau of Statistics of the Republic of Croatia, average life expectancy in the Republic of Croatia stood at 78.2 years in 2018 (7). According to 2011 census, the Croatian population is 41.7 years old on average, making the Croatian people one of the oldest peoples in Europe (8). The rise in life expectancy has increased the average age of the Croatian population by 10 years over the last 50 years. According to the 2011 census, the share of persons aged 65 or over $(17.7 \%)$ is, for the first time ever, higher than the share of young persons pertaining to the 0 -to-14 age group (15.2\%). Worldwide, in 2018 , the number of persons over 65 exceeded the number of children under 5 (6). The share of the very old has risen in the Republic of Croatia as well, from 0.8\% in 1953 to $3.9 \%$ in 2011 (7).

\section{Old Age: Sociological Issues}

An increase in the number of elderly people in a population also leads to greater need for long-term care, ultimately resulting in increasing health care and social care costs (5). Due to this fact, it is assumed that ageing will have a serious impact on social security and economy, with healthcare and social care costs reaching substantial proportions. One of the key characteristics of old age is retirement, i.e. greater social dependence (9).

The social context within which elderly persons and families function is also changing, which inter alia impacts the nature of certain types of social relations as well as the institutions providing part of the 
supporting infrastructure accessible to the elderly. Demographic and social trends - such as changes in propensity for marriage and starting a family, increasing frailty of human relations, disturbances within nuclear family, earlier adulthood - have an impact on the quantity and type of support available to the elderly and on their need for support (10).

An increasingly popular concept is ageism, a phenomenon characterized by lack of recognition or limitation of rights of the elderly (9). Ageism is segregation based on calendar age, non-acceptance of individual approach to the elderly after turning a certain age, determining capacity and attribution of social roles based on chronological age (9). People are prone to prejudice when they lack specific information concerning an elderly person other than their age, which is seemingly obvious (3). It is extraordinarily important to take into account the (lack of) capabilities of an elderly person that is being cared for, to eliminate prejudice concerning the elderly and to recognize their individuality, while responding in accordance with the specific needs of the elderly person (11).

\section{Objectives and Research Assumptions}

The objective of this research was to examine the impact of education in gerontology on the formation of students' attitudes towards elderly persons and the process of ageing. This examination was performed by means of a survey that looked into the respondents' education in gerontology, their demographic data, and the impact thereof on their attitudes towards the elderly. We wanted to determine whether differences in attitudes towards ageing and elderly persons existed among groups of students, and whether they were in any correlation with different levels of education in gerontology or with personal experience of living with the elderly. The first hypothesis was that attitudes of the School of Medicine students towards ageing were more positive compared to those of students of the Faculty of Maritime Studies of the University of Split, partly due to education in gerontology in the course of studies. The second hypothesis was that negative attitudes of the School of Medicine students towards ageing and the elderly was linked to the preferred specialization upon the completion of studies, and that students do not wish to specialize in gerontology as a result of such negative attitudes.

\section{Method}

\section{Sample}

The respondents were students of the University of Split enrolled in the School of Medicine or the Faculty of Maritime Studies in the academic year 2019/2020. The site of research was the University of Split. In total, 301 male and female students participated in the survey.

The informed consent was obtained from all subjects.

Authors confirm that all methods were carried out in accordance with relevant guidelines and regulation.

\section{Instrument}


Attitude is defined as an acquired, relatively permanent and stable organization of positive or negative emotions, evaluations and responses to an object. The structure of attitude consists of three components: cognitive component, which pertains to the knowledge concerning the object of attitude; emotional component, pertaining to the emotional perception of the object of attitude; behavioural component, which pertains to action in regard to the object of attitude (12).

As a means of looking into student attitudes, the authors conducted a cross-sectional, online survey, accessed by students of the two mentioned faculties, from all programmes and years of study. The survey was anonymous and participation voluntary. Out of a total 1,470 students of the Faculty of Maritime Studies in the academic year 2019/2020, 153 students responded to survey invitation (10.40\%). Of the total 1,216 students of the School of Medicine in the same academic year (in Medical Doctor, Pharmacy and Dental Medicine study programmes), 148 students completed the survey (12.58\%). The survey questionnaire consisted of three parts: the part looking into respondents' socio-demographic characteristics, the part examining their attitudes towards the elderly (Kogan's Attitudes Towards Old People Scale), and a knowledge/competence test (Palmer's questionnaire). Attitudes towards ageing and elderly persons were examined using the Kogan's OP scale. This scale contains a set of questions, where respondents are asked to choose the number that most accurately describes their stance on the question asked, the options being: 1 = Strongly disagree, 2 = Partly disagree, $3=$ Disagree, $4=$ Agree, $5=$ Partly agree, $6=$ Strongly agree. The same questionnaires were also used as a research instrument in the survey undertaken among Slovenian nursing students (13).

\section{Procedure}

Descriptive statistics methods were used, i.e. arithmetic mean and standard deviation for values in line with normal distribution; in case of deviation from normal distribution, the median was used as median value, and interquartile range as dispersion indicator. Distribution normalcy was examined by using the Kolmogorov-Smirnov test. Furthermore, $\chi 2$ test was used to test distribution balance based on sociodemographic characteristics. Differences in the level of knowledge and relations with the elderly were tested using the Mann-Whitney $U$ test and Kruskal-Wallis test as versions of parametric tests for determining normal distribution values. The impact of the selected characteristics on relations with the elderly was tested using logical regression, i.e. the stepwise procedure. Links between numerical values were determined using the Pearson correlation coefficient.

In the empirical part of this article, we tested the defined assumptions using quantitative methods in biomedicine. The paper also includes tables, detailing the structure of respondents' answers to survey questions.

Statistical software STATISTICA 12 (2013, StatSoft, US) was used for analytical purposes, while the level of significance was defined by value $p<0.05$.

\section{Results}


Table 1 shows the respondents' socio-demographic data.

Table 1

Respondents' socio-demographic characteristics

\begin{tabular}{|c|c|c|c|c|c|}
\hline & & $\mathbf{n}$ & $\%$ & $x^{2}$ & p* \\
\hline \multirow[t]{2}{*}{ Sex } & $\mathbf{F}$ & 160 & 53.16 & \multirow[t]{2}{*}{1.20} & \multirow[t]{2}{*}{0.273} \\
\hline & M & 141 & 46.84 & & \\
\hline \multirow[t]{3}{*}{ Age Group } & $18-22$ & 215 & 71.43 & \multirow[t]{3}{*}{208.05} & \multirow{3}{*}{$\begin{array}{l}<.001 \\
0.001\end{array}$} \\
\hline & $23-27$ & 67 & 22.26 & & \\
\hline & 33 and above & 19 & 6.31 & & \\
\hline \multirow[t]{2}{*}{ Domicile } & Urban area & 241 & 80.07 & \multirow[t]{2}{*}{108.84} & \multirow{2}{*}{$\begin{array}{l}<.001 \\
0.001\end{array}$} \\
\hline & Rural area & 60 & 19.93 & & \\
\hline \multirow[t]{4}{*}{ Course enrolled } & Medicine & 100 & 33.22 & \multirow[t]{4}{*}{269.15} & \multirow{4}{*}{$\begin{array}{l}<.001 \\
0.001\end{array}$} \\
\hline & Dental Medicine & 31 & 10.23 & & \\
\hline & Pharmacy & 17 & 5.65 & & \\
\hline & $\begin{array}{l}\text { Faculty of Maritime } \\
\text { Studies }\end{array}$ & 153 & 50.83 & & \\
\hline \multirow[t]{6}{*}{ Year of study } & 1st year & 176 & 58.47 & \multirow[t]{6}{*}{403.75} & \multirow{6}{*}{$\begin{array}{l}<.001 \\
0.001\end{array}$} \\
\hline & 2nd year & 30 & 9.97 & & \\
\hline & 3rd year & 49 & 16.28 & & \\
\hline & 4th year & 3 & 1.00 & & \\
\hline & 5th year & 30 & 9.97 & & \\
\hline & 6th year & 13 & 4.32 & & \\
\hline \multirow[t]{2}{*}{ Secondary education } & Grammar School (Lycee) & 174 & 57.81 & \multirow[t]{2}{*}{7.34} & \multirow[t]{2}{*}{0.007} \\
\hline & Vocational & 127 & 42.19 & & \\
\hline \multirow[t]{2}{*}{ Education in Gerontology } & No & 256 & 85.05 & \multirow[t]{2}{*}{147.91} & \multirow{2}{*}{$\begin{array}{l}<.001 \\
0.00\end{array}$} \\
\hline & Yes & 45 & 14.95 & & \\
\hline \multirow{2}{*}{$\begin{array}{l}\text { Experience living with an elderly } \\
\text { person } \\
(>65)\end{array}$} & No & 92 & 30.56 & \multirow[t]{2}{*}{45.48} & \multirow[t]{2}{*}{$\begin{array}{l}< \\
0.001\end{array}$} \\
\hline & Yes & 209 & 69.44 & & \\
\hline
\end{tabular}


Of the overall number of respondents (301), 53.16\% were female and $46.84 \%$ were male students, and the difference is not statistically significant $(\chi 2=1.20 ; p=0.273)$.

In terms of age, the greatest number of respondents fall in the 18-22 age group. In fact there are 196 more students of this age group than of the 33 and above $(19 ; 6.31 \%)$, which is the least represented student age-group in the sample $(\chi 2=208.05 ; p<0.001)$.

The greatest number of students (153 or $50.83 \%$ ) are enrolled at the Faculty of Maritime Studies, while only $5.65 \%$ (17 students) are enrolled at the Faculty of Pharmacy. Tests confirm the uneven distribution of students per study program $(\chi 2=269.15 ; p<0.001)$.

Most of the respondents are 1 st year students: there are 173 more 1 st year than 4 th year students. $A$ statistically relevant difference has been confirmed by tests $(\chi 2=403.75 ; p<0.001)$.

The majority of the respondents had attended a grammar school (174:127): 47 more than a vocational secondary school, which is a statistically significant difference $(\chi 2=7.34 ; p=0.007)$.

The number of students who had no training in gerontology was significantly higher $(211 ; 256 / 49)$ and tests confirm a statistically relevant difference $(\chi 2=147.91 ; p<0.001)$.

Significantly more respondents have experience living with the elderly $(\geq 65)-209$, compared with the 92 who have no such experience. The difference is statistically significant $(x 2=45.48 ; p<0.001)$.

Table 2

Difference in students' attitudes according to the course enrolled

\begin{tabular}{|c|c|c|c|c|c|c|}
\hline & \multicolumn{4}{|l|}{ Faculty } & \multirow[t]{3}{*}{ Z } & \multirow[t]{3}{*}{$\mathrm{p}^{*}$} \\
\hline & \multicolumn{2}{|c|}{ Maritime Studies } & \multicolumn{2}{|c|}{ School of Medicine } & & \\
\hline & Median & IQR & Median & IQR & & \\
\hline Kogan's OP Scale & 120.00 & $\begin{array}{l}(116.00- \\
128.00)\end{array}$ & 126.00 & $\begin{array}{l}(119.00- \\
135.00)\end{array}$ & 4.17 & $<.001$ \\
\hline $\begin{array}{l}\text { Palmer's competence } \\
\text { test }\end{array}$ & 62.79 & $(58.14-69.77)$ & 67.44 & $(2.79-74.41)$ & 5.32 & $<.001$ \\
\hline
\end{tabular}

Table 2 shows the difference in results depending on the course enrolled, based on Kogan' OP Scale and Palmer's competence test. According to Kogan's Scale, the results are higher by 6 points for students of Medicine than for students of Maritime Studies $(Z=4.17 ; p<0.001)$, which means that medicine students have more positive attitudes towards the elderly. Medicine students got 4.65 points more than their Maritime Studies colleagues $(Z=5.32 ; p<0.001)$ in Palmer's competence test as well, which means that they know more about ageing and the elderly. These differences in test results in two groups of 
respondents serve to prove that there is a correlation between positive attitudes and knowledge about ageing and the elderly in students of medical sciences.

Table 3

Differences in students' attitudes depending on demographic characteristics

\begin{tabular}{|c|c|c|c|c|c|c|}
\hline & \multicolumn{4}{|l|}{ Sex } & \multirow[t]{3}{*}{$\mathbf{Z}$} & \multirow[t]{3}{*}{$\mathrm{p}^{*}$} \\
\hline & \multicolumn{2}{|l|}{ Male } & \multicolumn{2}{|l|}{ Female } & & \\
\hline & Median & IQR & Median & IQR & & \\
\hline Kogan's OP scale & 121.00 & $\begin{array}{l}(117.00- \\
129.00)\end{array}$ & 125.00 & $\begin{array}{l}(116.00- \\
135.00)\end{array}$ & 2.21 & 0.027 \\
\hline $\begin{array}{l}\text { Palmer's competence } \\
\text { test }\end{array}$ & 62.79 & $(58.14-69.77)$ & 67.44 & $(62.79-72.09)$ & 3.97 & $\begin{array}{l}< \\
0.001\end{array}$ \\
\hline
\end{tabular}

Table 3 shows the differences in results achieved by students of different sex. The Kogan scale median is by 4 points lower in men than in women $(Z=2.21 ; p=0.027)$.

According to the Palmer's scale, the median in by 4.65 points lower in men than in women $(Z=3.97 ; p<$ 0.001). These results indicate that male students have less positive attitudes and a lower degree of knowledge about ageing and the elderly than their female counterparts, and the difference is statistically significant.

Table 4

Differences in students' attitudes depending on their domicile

\begin{tabular}{|c|c|c|c|c|c|c|}
\hline & \multicolumn{4}{|c|}{ Domicile } & \multirow[t]{3}{*}{ Z } & \multirow[t]{3}{*}{$\mathrm{p}^{*}$} \\
\hline & \multicolumn{2}{|c|}{ Urban area } & \multicolumn{2}{|c|}{ Rural area } & & \\
\hline & Median & IQR & Median & IQR & & \\
\hline Kogan's OP scale & 123.00 & $\begin{array}{l}(117.00- \\
134.00)\end{array}$ & 120.00 & $\begin{array}{l}(116.00- \\
126.50)\end{array}$ & 2.21 & 0.027 \\
\hline $\begin{array}{l}\text { Palmer's competence } \\
\text { test }\end{array}$ & 65.11 & $(60.47-72.09)$ & 65.12 & $(60.47-69.77)$ & 1.06 & 0.288 \\
\hline
\end{tabular}

Table 4 shows the difference in results depending on the respondents' domicile. The median value according to the Kogan scale is by 3 points higher for respondents living in urban areas $(Z=2.21 ; p=$ 0.027), which shows that they have more positive attitudes towards ageing and the elderly than respondents living in rural areas. According to the Palmer's test, the median is by 0.01 points higher in respondents living in rural areas, but without a statistically significant difference $(Z=1.06 ; p=0.288)$. 
Table 5

Differences in students' perception depending on their age

\begin{tabular}{|c|c|c|c|c|}
\hline \multicolumn{5}{|c|}{ Palmer's - competence test } \\
\hline & Median & IQR & $\mathrm{H}$ & $\mathrm{p}^{*}$ \\
\hline $18-22$ & 65.12 & $60.47-69.77$ & 5.46 & 0.654 \\
\hline $23-27$ & 67.44 & $62.79-74.42$ & & \\
\hline 33 and older & 67.44 & $62.79-72.09$ & & \\
\hline
\end{tabular}

Table 5 shows the different results depending on age groups. According to the Palmer's competence test, students aged 18-22 achieved poorer results than their counterparts from the 23-27 or 33 and older age group $(H=5.46 ; p=0.654)$. Such results indicate that older students know somewhat more about ageing and the elderly, but the difference is not statistically significant.

Table 6

Comparison of Kogan scores according to student age group

\begin{tabular}{|lllll|}
\hline Kogan score & & & & \\
\cline { 1 - 4 } & Median & IQR & H & p* \\
\cline { 1 - 3 } 18-22 & 121.00 & $(116.00-132.00)$ & 12.80 & 0.002 \\
\cline { 1 - 3 } 33 and older & 121.00 & $(116.00-128.00)$ & & \\
\cline { 1 - 4 } *Kruskal-Wallis test & & & \\
\hline
\end{tabular}

Table 6 shows the difference in results between different age groups. Kogan scores are by 6 points higher in respondents aged 23-27 than in those aged 18-22 or 33 and older $(H=12.80 ; p=0.002)$. Our results indicate that older students have more positive attitudes towards ageing and the elderly, and the difference is statistically significant. 
Table 7

Differences in students' perception depending on education in gerontology

Education in gerontology

$Z \quad p^{*}$

\begin{tabular}{|lllllll|} 
& \multicolumn{2}{c}{ Some } & \multicolumn{5}{c}{ None } & \\
\cline { 2 - 5 } & Median & IQR & Median & IQR & \\
Kogan's OP score & 129.00 & $\begin{array}{l}(120.00- \\
135.00)\end{array}$ & 121.50 & $\begin{array}{l}(116.00- \\
132.00)\end{array}$ & 2.65 & 0.008 \\
$\begin{array}{lllllll}\text { Palmer's competence } \\
\text { test }\end{array}$ & 65.12 & $(62.79-74.42)$ & 65.12 & $(60.47-72.09)$ & 1.50 & 0.134 \\
\hline *Mann-Whitney U test & & & & & & \\
\hline
\end{tabular}

Table 7 shows the difference in results depending on previous education in gerontology. The median value according to the Kogan score is by 7.50 points higher in respondents who have attended gerontology training than in those who had none $(Z=2.65 ; p=0.008)$. Respondents who had been educated in gerontology show a more positive attitude and more knowledge on ageing and the elderly, and the difference is statistically significant, which confirms the first hypothesis of our research.

Table 8

Differences in student attitudes depending on their experience of life with the elderly

$\begin{array}{lll}\text { Experience of life with the elderly } & Z & p^{*}\end{array}$

\begin{tabular}{|lllllll|}
\hline & \multicolumn{2}{c}{ Some } & \multicolumn{3}{c}{ None } & \\
\cline { 2 - 6 } & Median & IQR & Median & IQR & & \\
\hline Kogan score & 124.00 & $(117.00-133.00)$ & 120.00 & $(115.50-133.00)$ & 1.36 & 0.173 \\
\hline Palmer's competence & 65.12 & $(60.47-72.09)$ & 65.12 & $(60.47-72.09)$ & 0.76 & 0.448 \\
\hline *Mann-Whitney U test & & & & & & \\
\hline
\end{tabular}

Table 8. shows the difference in student attitudes depending on their experience of life with the elderly.

Gender played a statistically important impact on values according to the Kogan scale: female students had 1.898 times greater chances of Kogan scores higher than $133(B=1.898 ; p=0.038)$, which indicates a more positive attitude towards ageing and the elderly in females than in males, and the difference is statistically relevant. With every further year of university, the likelihood of a Kogan scale score higher than 133 increases by $1.234(B=1.234 ; p=0.017)$, which means that the longer a respondent has been studying, the more positive their attitude will be, and the difference is statistically relevant.

The median Kogan score is by 4 points higher in respondents who have lived with an elderly, but the difference is statistically irrelevant $(Z=1.36 ; p=0.173)$. 
Palmer's competence test results show the same median in both observed groups, which means that there are no statistically relevant differences in the level of knowledge about ageing and the elderly between the sexes $(Z=0.76 ; p=0.448)$.

From the point of view of the preferred specialization, the highest Kogan score concerning ageing and the elderly, and consequently the most positive attitude, was recorded in respondents who want to become radiology specialists, while those interested in emergency medicine had the lowest score, but the results are not statistically relevant $(H=14.62 ; p=0.931)$.

\section{Table 9}

Differences in students' perception depending on their preferred specialization following the completion of their studies

\begin{tabular}{|c|c|c|c|c|c|}
\hline Preferred specialization & $\mathbf{N}$ & Median & IQR & $\mathrm{H}$ & $p^{*}$ \\
\hline Radiology & 2 & 141.00 & $134.00-148.00$ & \multirow[t]{19}{*}{14.62} & \multirow[t]{19}{*}{0.931} \\
\hline Clinical Pharmacy & 2 & 133.00 & $125.00-141.00$ & & \\
\hline Internal Medicine & 15 & 131.00 & $117.00-137.00$ & & \\
\hline Family Medicine & 10 & 130.50 & $120.00-142.00$ & & \\
\hline Sports Medicine & 2 & 130.50 & $119.00-142.00$ & & \\
\hline Psychiatry & 6 & 130.00 & $125.00-135.00$ & & \\
\hline Dermatology & 8 & 128.00 & $109.00-136.00$ & & \\
\hline Pediatrics & 9 & 128.00 & $119.00-132.00$ & & \\
\hline Geronotology & 2 & 127.00 & $119.00-135.00$ & & \\
\hline Gynecology & 8 & 126.50 & $115.50-141.00$ & & \\
\hline Neurology & 3 & 126.00 & $112.00-142.00$ & & \\
\hline Cardiology & 6 & 124.50 & $122.00-133.00$ & & \\
\hline Oncology & 8 & 123.50 & $117.00-131.50$ & & \\
\hline Surgery & 15 & 123.00 & $117.00-135.00$ & & \\
\hline Anesthesiology & 2 & 121.00 & $121.00-121.00$ & & \\
\hline Infectious Disease Medicine & 1 & 121.00 & $121.00-121.00$ & & \\
\hline Pathology & 1 & 113.00 & $113.00-113.00$ & & \\
\hline Microbiology & 1 & 108.00 & $108.00-108.00$ & & \\
\hline Emergency Medicine & 1 & 106.00 & $106.00-106.00$ & & \\
\hline
\end{tabular}


Table 9 shows the results based on professional preferences after graduation.

Tests showed no statistically relevant difference $(H=14.62 ; p=0.931)$, which means that attitudes towards ageing and the elderly are not linked to professional preferences/preferred specialization, rejecting the second hypothesis. This outcome might be the consequence of poor information about specialization opportunities upon the completion of studies.

\section{Discussion}

The attitudes and effect of gerontology education on students of Medicine and of Maritime Studies in Split have been examined using Kogan's scale and Palmer's questionnaire. In addition to the impact of knowledge, the questionnaire also examined the effect of some socio-demographic factors on the formation of attitudes concerning ageing and elderly persons among students (3).

School of Medicine students were selected due to the possibility of their earlier education in the area of gerontology, and due to awareness of social groups with increased needs. Students of the Faculty of Maritime Studies were selected as a comparative group, representative of the bulk of the population with no gerontology education during the course of their studies.

Two hypotheses were defined. According to the first hypothesis, attitudes of the School of Medicine students concerning ageing are more positive than those of students of the Faculty of Maritime Studies of the University of Split, partly due to gerontology education in the course of studies, and this hypothesis has been confirmed. The second hypothesis was that negative attitudes of the School of Medicine students concerning ageing and the elderly is linked with the preferred specialization upon the completion of studies, and that students do not wish to become specialized in gerontology due to their negative attitude. This hypothesis has been rejected.

Attitudes concerning ageing and elderly persons are formed under the influence of various factors (14). Since the number of elderly persons is on the rise, there is a growing need to change negative attitudes among the public towards ageing and persons of age (15). Academic findings and research see the average age of the population of a given community as the first indicator and benchmark of the quality of life. Extension of life expectancy is a major achievement. Each individual, regardless of age, wants to live as many years as possible, but without the negative connotations of old age, and with the highest achievable quality of life (16).

When considering the elderly, it is often forgotten that most people in this population group are in the period of early old age, when changes caused by ageing are not pronounced to such a degree that they would substantially limit their daily activities, except in cases of complications caused by chronic illness (11).

In this study, students expressed their own attitudes concerning ageing and elderly persons using the Kogan scale, by selecting the number closest to their perception of a given claim. They agreed the most 
with the claim that most elderly persons have their own habits that cannot be changed. On the other hand, students agreed the least with the claim that most elderly persons allow their homes to become shabby and unpleasant.

The impact of knowledge on the formation and change of attitudes has already been proven (17). Palmer's questionnaire comprised claims that respondents assessed as true or false. There were 34 claims where more than $50 \%$ of the respondents knew the correct answer, and four claims where the majority of the respondents did not know the correct answer. Students' responses included stereotypes and fallacies most frequently connected with social life of the elderly, and correct answers were typically those pertaining to the physical condition of organism and changes arising due to ageing.

In case of our respondents, there is a positive and statistically significant link between the results of Kogan and Palmer scales, i.e. persons with a higher degree of knowledge concerning persons of age have more positive attitudes towards ageing and the elderly, and the opposite is true as well. Fallacies in connection with ageing include lack of knowledge on the plasticity of the central nervous system and decay of brain activity excluding neurological disorders (18). Elderly persons can learn, but their motivation and learning methods differ, which requires the adaptation of teaching methods to their age and needs. While the manner in which they memorize new data and written material can be taken into account through proper teacher training, various games help maintain mental fitness, just as in other organic systems (19). It is important to point out that elderly persons do not memorize new data as well as young persons; however, their learning capacity as well as long-term memory are preserved. It is therefore extraordinarily important to initially assess the psychological independence of a person, and to exclude depression and neurological disorders that are frequent in old age (11).

Among our respondents, a more positive attitude towards ageing and the elderly was recorded in students Medicine than in students of Maritime Studies.

Age, sex and domicile have also shown to have an impact on the formation of attitudes concerning ageing and the elderly (20). Male students scored lower median values in both Kogan scale and Palmer questionnaire, when compared to female students. Furthermore, female students exhibit a more positive attitude towards ageing and the elderly compared to their male counterparts (1.898 times higher probability for Kogan scores higher than $133 ; B=1.898 ; p=0.038$ ). In most cultures, the role of women in family is to care for the children, the ill, the old and disabled persons; as a result of upbringing, female children have a pronounced sensibility for the needs of other family members (21).

Each subsequent year of study increases the probability that a person will achieve a Kogan scale score higher than 133 by 1.234 times $(B=1.234 ; p=0.017)$, which points to a conclusion that a more positive attitude among students is developed in the course of years of study.

Respondents from urban settlements have shown a more positive attitude towards ageing and the elderly compared to respondents residing in rural settlements, but difference in knowledge (Palmer's test) has not been determined. This result is contrary to our expectations. In fact, rural areas are frequently 
perceived through the prism of a traditional form of life and nurturing of family values, where care for the needs of each family member is pronounced and, in line with that, we expected respondents living in rural areas to have more positive attitudes concerning ageing and the elderly.

Students were divided into three age groups. One age group comprised students from 18 to 22 years of age; one group from 23 to 27 years of age; and one group comprised persons older than 33 . The youngest age group (18 to 22 years of age) has shown a lower level of Palmer scale results (knowledge) compared to older age groups. The highest results under Kogan's scale were achieved by the 23-27 age group, which means that attitudes towards ageing and the elderly turn more positive as life experience increases. However, if students have no gerontology training foreseen in their study programme, the chance for formation of positive attitudes will remain unused (22).

Experience of life with the elderly did not result in differences in Kogan scale and Palmer questionnaire results, between persons who have such an experience and those who do not.

Desired specialization among students of the School of Medicine does not impact the attitude concerning ageing and the elderly. The reason why relatively few students choose Gerontology as future specialization in the course of professional life is probably grounded in insufficient information concerning the opportunities and education methods within this branch of medicine, and probably also due to insufficient attractiveness of the specialization (23).

We have compared the results obtained through our survey with two existing pieces of research. An earlier research from Slovenia compared attitudes towards ageing and the elderly between Croatian and Slovenian nursing students (13). The total number of respondents in the Slovenian study amounted to 825 nursing students, 408 of whom were from Croatia and 417 from Slovenia. The same questionnaires were applied as in our research. As regards important characteristics of the two groups, it is important to point out that $22.55 \%$ of the Croatian student group had no education concerning care for the elderly, compared with only $8.39 \%$ of the total number of Slovenian students covered by the study who had no such education. In accordance with that, $81.86 \%$ of Croatian students believe that additional educational programs are needed concerning ageing and the elderly, with $70.74 \%$ of Slovenian students believing the same.

Differences in students' attitudes towards ageing and the elderly have been identified as depending on training in gerontology, i.e. on differences in educational programmes between Croatia and Slovenia. Slovenian respondents have substantially better indicators as regards perception and attitudes of students compared to Croatian respondents/students, while respondents with prior education in care for the elderly also exhibit substantially better attitudes and perception compared to those who had no prior education (13).

Whenever results differ depending on sex, domicile, type of study and employment, such results obtained in the Slovenian study are similar to the ones identified in our research. Answers from the Slovenian survey show that female respondents perceive ageing and elderly persons substantially better than men. 
However, in the Slovenian study, respondents residing in rural areas have shown better results (more positive attitudes and a higher level of knowledge) compared to those living in urban areas, which is opposite to our findings.

Links between professional preferences following the completion of one's studies on the one hand, and attitudes towards ageing and the elderly on the other, have not been found in the discussed Slovenian survey either.

Attitudes of medicine students towards ageing and elderly persons were also examined in a study performed in Turkey, involving students of the School of Medicine. The research encompassed 324 students of the fourth, fifth and sixth year of medical school, and attitudes were examined using the Kogan scale (24). The Turkish respondents' median value according to Kogan's scale was lower than that of our respondents' from the School of Medicine, which points to a more benevolent attitude towards ageing and the elderly at the University of Split. In addition, the Kogan scale result was higher for female students compared with male students, which is identical to our results. No differences were found concerning other socio-demographic factors. The use of the same instrument for the examination of attitudes in three culturally different environments is interesting in terms of the diverse character of obtained results. Differences in Kogan scores for the examined attitudes, revealed when comparing the obtained data, point to the need to educate young people and to adapt educational programmes. Through this research, we have shown that knowledge is the only effective measure in combating prejudice and negative stereotypes. Correct information is the only cure against ill-informed beliefs. That is why young people need to be made aware of societal problems and of the increasingly older community, as early as possible. Moreover, Medicine, Dental Medicine and Pharmacy students need to be better acquainted with the possibilities of resolving health issues of elderly persons through study programmes (23).

The comparative analysis of surveys is all the more interesting when taking into account that respondents were chosen among students of Nursing (Slovenia and Croatia) and Schools of Medicine (in Croatia and Turkey). Our research provides an additional dimension, by providing a comparison with students of the Faculty of Maritime Studies, whose education is not founded on healthcare programmes, and whose attitudes are not impacted by their professional knowledge, but rather by general health literacy. A positive impact on the formation of attitudes and knowledge shown in the survey has been found among first-year School of Medicine students who obtained education in the optional course of Gerontology.

Our research has found that there is a difference in attitudes between students who were exposed to educational content from gerontology and those who were not. The group that was not exposed to gerontology training had a negative attitude compared to the group had had gerontology lessons. This paper confirms that the provision of truthful and timely information is the best method of preventing negative attitudes and stigmatization of groups that have increased needs in society. 


\section{Potential Limitations and Gaps}

This is a cross-sectional study involving the students of two faculties of the University of Split at one point in time. Although the ratio of males and females among respondents is approximately the same (160/53.16\% females; $141 / 46.84 \% ; p=0.273$ males) it is possible that the students of Medicine have more positive attitudes towards and more knowledge of ageing and the elderly due to the fact that at that faculty there is a greater share of female than of male students. The female group of students is also made up of a part of female students of Maritime Studies since the overall number of Medical School students was 148 , and the total number of female respondents 160 . According to a research conducted in Croatia, males make up the majority of enrolled students $(73.1 \%)$ only in regular and full-time university specialist courses in the field of technical sciences. The highest ratio of females at the Faculty of Maritime Studies is in the Maritime Management study program. In areas such as biomedicine and health, males make up less than a third of all students enrolled: $28.06 \%(25)$, and the situation at the University of Split is in line with the trends at country level.

\section{Conclusion}

In the research conducted, the connection between Kogan scores and Palmer's competence tests is positive and statistically relevant, which only goes to show that individuals who know more about the elderly also have more positive attitudes towards ageing and the elderly and vice-versa $(r=0.297 ; p<$ 0.001). The attitudes among students of medical sciences are generally more positive in two categories: they score 6 points higher in the Kogan scale than their Maritime Studies colleagues and have 4.65 points higher test results in Palmer's competence questionnaire, which means that individuals who know more about the issue at stake tend to have a more positive attitude towards it. Students' attitudes and knowledge differ depending on their demographic characteristics (age, sex, domicile, year at university). The median value for the Kogan scale is lower in male than in female students, which defines the female students as comparatively positive. The Kogan scale median value is higher in respondents living in urban areas than for those living in rural areas, but no difference has been recorded according to the Palmer's scale. Similar results have been obtained when comparing age groups 18-22 and 33 and older.

Differences in attitudes exist depending on whether students have had gerontology courses: it has been proven that students who attended such courses have a more positive attitude than those who had none. The median according to the Palmer's competence test is the same for both observed groups $(Z=1.50 ; p$ $=0.134)$. No differences have been recorded in students' attitude towards ageing depending on their experience of life with the elderly. Of the 100 respondents from the School of Medicine, only one chose a specialization in gerontology. Negative attitudes of medicine students towards ageing and the elderly are not related to their professional preferences or choice of specialization after graduation. The ageing perception model confirms that a whole range of factors (demographic factors, education, courses and different contents that students have been exposed to, life with an elderly individual) has an important impact on the formation of attitudes towards old age and ageing. 


\section{Declarations}

Acknowledgements

Not applicable.

\section{Authors' contributions}

IJT shaped the study's conception and design. MB collected and processed data from the questionnaires. All authors were included in the interpretation of data, critical analysis, literature review, and manuscript drafting. RM and NKP revised the manuscript critically. All authors read and approved the final manuscript.

\section{Funding}

No funding was obtained for this study.

\section{Availability of data and materials}

The datasets used and/or analysed during the current study are available from the corresponding author on reasonable request.

\section{Ethics approval and consent to participate}

Ethical approval was obtained from the Ethic Committee of School of Medicine, Split

University (3/10/2020, CLASS 003-08/20-03/0005; File No. 2181-198-03-04-20-0026).

The informed consent was obtained from all subjects.

\section{Consent for publication}

Not applicable.

\section{Competing interests}

The authors declare that they have no competing interests.

\section{Author details}

IJT is an assistant professor of public health at School of Medicine, Department of Public Health, University of Split, Šoltanska 2, 21000 Split, Croatia.

MB is a student at School of Medicine, University of Split, Šoltanska 2, 21000 Split, Croatia.

RM is a full professor of public health at the Department of Public Health, School of Medicine, and she is cross-appointed to the Faculty of Maritime Studies, University of Split, Šoltanska 2, 21000 Split, Croatia. 
NKP is an associate professor at the ENT Department of the Clinical Hospital Split and at School of Medicine, University of Split, Šoltanska 2, 21000 Split, Croatia.

\section{References}

1. Lučanin D. The Experience of Ageing (in Croatian). Naklada Slap: Jastrebarsko; 2003.

2. Duraković Z. Geriatrics - Medical Care for the Elderly (in Croatian). CT-poslovne informacije d.o.o.: Zagreb;2007.

3. Gonçalves DC, Guedes J, Fonseca AM, Pinto FC, Martín I, Byrne GJ, et al. Attitudes, knowledge, and interest: preparing university students to work in an aging world. International Psychogeriatrics, 2011; 23:(2): 315-32. https://doi.org/10.1017/S1041610210001638

4. Tomek-Roksandić S. Glossary of Selected Professional Terms in Gerontology (in Croatian). Zagreb: Nastavni zavod za javno zdravstvo dr. Andrija Štampar; 2016. http://www.stampar.hr/sites/default/files/Aktualno/novosti/2016/Docs/glosarij_16.09_2016.pdf

5. Paskaleva D, Tufkova S. (2017). Social and medical problems of the elderly. J Gerontol Geriatr Res. 2017;6(3):3-5. https://doi.org/10.4172/2167-7182.1000431

6. World Population Prospects, Highlights. United Nations: New York; 2019. https://population.un.org/wpp/Publications/Files/WPP2019_Highlights.pdf

7. Census of Population, Households and Dwellings 2011: Population by Sex and Age (in Croatian). State Statistics Bureau of the Republic of Croatia: Zagreb; 2013. http://www.dzs.hr/Hrv_Eng/publication/2012/SI-1468.pdf

8. Population structure and ageing. Eurostat; 2019.

9. https://ec.europa.eu/eurostat/statistics-explained/index.php/Ageing_Europe__statistics_on_population_developments

10. Brajković L. (2010). Life Satisfaction Indicators in Older Adulthood (in Croatian). Doctoral dissertation. University of Zagreb: Zagreb School of Medicine; 2010. http://medlib.mef.hr/id/eprint/824.

11. Waite L, Plewes JT. New directions in the sociology of aging. Washington: National Academies Press;2013. https://www.ncbi.nlm.nih.gov/books/NBK184353/.

12. Mlinac ME, Feng MC. (2016). Ageing and health. Assessment of Activities of Daily Living, Self-Care, and Independence. Archives of Clinical Neuropsychology. 2016;31(6):506-516. https://doi.org/10.1093/arclin/acw049

13. Petz B. Psychological dictionary. Zagreb: Prosvjeta; 1992. "Psihologijski rječnik", Prosvjeta, Zagreb.

14. Veronek J. The Impact of Different Factors on Perception Nursing Students Toward Aging Comparative Analysis of Slovenia and Croatia (in Croatian). Doctoral dissertation. Maribor: Alma Mater Europea; 2019.

15. Rukewe A, Abebe WA, Fatiregun AA, Kgantshang M. (2017). Specialty preferences among medical students in Botswana. BMC Res Notes 2017; 10: 195. https://doi.org/10.1186/s13104-017-2523-y 
16. Narushima M, Liu J, Diestelkamp N. Lifelong learning in active ageing discourse: its conserving effect on wellbeing, health and vulnerability. Ageing Soc. 2018;38(4): 651-675. doi: $10.1017 /$ S0144686X16001136

17. Bilgili N, Arpaci F. Quality of life of older adults in Turkey. 2014; 59(2):415-421. https://doi.org/10.1016/j.archger.2014.07.005

18. Palumbo R, Adams RB, Hess U, Kleck RE, Zebrowitz L. Age and Gender Differences in Facial Attractiveness, but not Emotion Resemblance, Contribute to Age and Gender Stereotypes. Front. Psychol; 2017. https://doi.org/10.3389/fpsyg.2017.01704

19. Dumurgier J, Tzourio C. Epidemiology of neurological diseases in older adults. Rev Neurologique. 2020; 176(9):642-648. doi: 10.1016/j.neurol.2020.01.356

20. Ahjin K, Sharan BM. Motivations for Learning among Older Adults in a Learning in Retirement Institute. Educational Gerontology. 2010;6:441-445. https://doi:10.1080/03601270490445069

21. Meira EC, Reis LA, Gonçalves LH, Rodrigues VP, Philipp R. Women's experiences in terms of the care provided to dependent elderly: gender orientation for care. Esc Anna Nery. 2017; 21(2):e20170046. https:// doi.org/10.5935/1414-8145.20170046

22. Barrett A, Von Rohr C. Gendered Perceptions of Aging: An Examination of College Students. The International Journal of Aging and Human Development. 2008;67(4):359-86. DOI: 10.2190/AG.67.4.d

23. Bordone $V$, Arpino B, Rosina A. Forever young? An analysis of the factors influencing perceptions of ageing. Ageing \& Society. 2020;40(8):1669-1693. https://doi.org/10.1017/S0144686X19000084

24. Khader Y, Al-Zoubi D, Amari Z, Alkafagei A, Khasawneh M, Burgan Set al. (2008). Factors affecting medical students in formulating their specialty preferences in Jordan. BMC Medical Education. 2008; 8:32. https://doi:10.1186/1472-6920-8-32

25. Elbi H, Altan S, Rahman S, Cengiz Özyurt B, Şahin S, Çam FS. The attitudes of medical students toward the elderly. Turkish Journal of Geriatrics, 2015;18(4):299-304.

26. Jokić B, Ristić Dedić Z. Becoming a Student in Croatia (in Croatian). Zagreb, AZVO. 2014. https://www.azvo.hr/images/stories/publikacije/Postati_student_u_Hrvatskoj.pdf 